\title{
Basics of scientific and technical writing
}

By Morteza Monavarian

\section{Introduction to scientific/ technical writing}

Scientific/technical writing is an essential part of research. The outcome of a research activity should be shared with others in the form of scientific paper publications; some ideas require a patent to reserve the implementation rights; and almost any research activity requires a funding source, for which a grant proposal is necessary. Therefore, it is crucial to know the differences among writing papers, patents, and grant proposals and how to prepare them in a research environment (Figure 1).

\section{Papers}

The publication of papers is a standard way to share knowledge and transfer methods in scientific communities, thus a pivotal part of any research activity, especially in an academic environment. In industry, where financial profit is a key factor, patents are possibly more favorable.

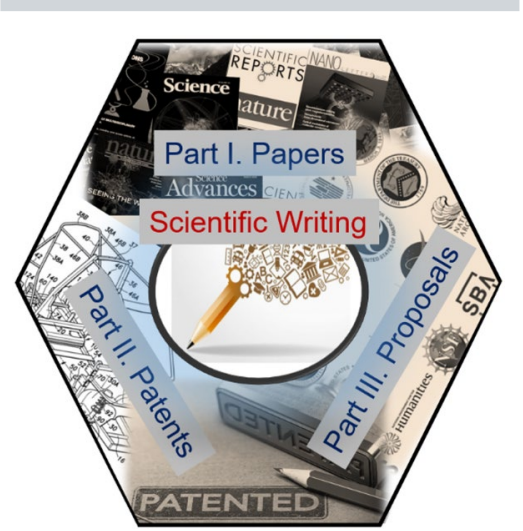

Figure 1. Three major types of scientific/ technical writing covered in the threepart series.

\section{Types of paper publications}

There are different types of paper publications, depending on the content, audience, purpose, length, and scope: original research, review articles, invited articles, conference proceedings, comments/ errata, and press releases (Figure 2).

Original research articles may be published in journals or conference proceedings (or preprints in arXiv) and target specific audiences within a field of research. Journal research papers require peer review that typically involves an editor and two reviewers. For conference proceedings, there is usually no direct peer-review process, but the work has to be presented in the corresponding conference to be eligible for publication.

In contrast to original research articles, which are written on special topics within a field of research, review articles normally cover an overview of research and tend to be longer. Review articles do not necessarily reflect on novel data or ideas and could be similar to a book chapter. However, unlike review articles, book chapters or books are usually written when the target field of research is fully established. In a review paper, figures are typically not original and reprinted from other publications, for which a copyright permission from the original publishing journal is required.

Invited articles are written in response to an invitation by a journal editor or a conference organizer in a specific field of research or for a special issue. An invited article could be a review article or original research. Invited articles are normally written by peers or researchers with significant contributions to a field of research.

Other items published include comments or errata. The purpose of a comment on a published article is to bring points of criticism to the attention of the readers as well as the authors of the original article. The comments can be published in the same journal as the original paper. Errata correct mistakes in an article after publication.

Finally, press releases target a more general audience and normally report on a review/overview of recently published research. The author of the press release is not the same as that of the original article. Unlike peer-reviewed research articles, press release articles are usually not citable.

\section{Writing structures and styles}

Different articles have different structures. A research article typically consists of a title, author list and affiliations, abstract, main body, conclusions, acknowledgments, and references.

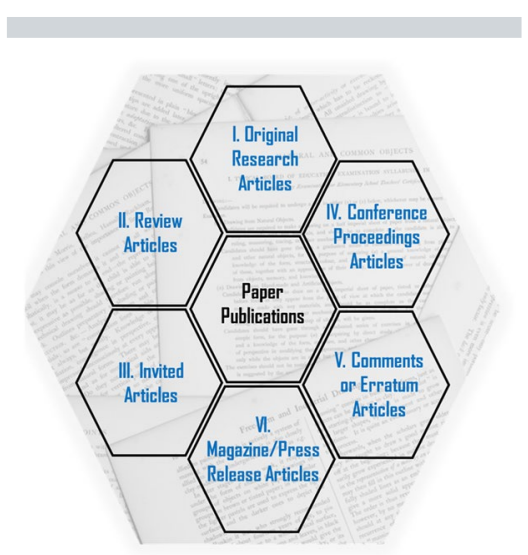

Figure 2. Six major types of paper publications. 
A good title should be concise, to the point, and free of abbreviations. Author lists and affiliations include whoever has intellectually contributed to the paper (identifying at least one corresponding author and email address), with the order approved by all of the co-authors. A good abstract should give a full, but short, overview of the work with both qualitative and quantitative data summaries. An abstract should be self-contained, meaning it should not require a referral to a reference or figure. Abstracts are usually written in the present tense and have an active voice.

Unlike letters with no sections within the main body, the main body of research articles normally contains several sections (e.g., introduction, methods and approach, results, and discussions). The introduction should contain a deep literature review of the field as the basis for motivating the current work. The last paragraph of the introduction usually summarizes what to expect from the article. The following sections will demonstrate study methods, results, and discussions/interpretations of the results, including plots, tables, and figures.

Conclusions summarize the findings of the paper and may point out any future directions. The acknowledgment lists all funding support and gratitude toward anyone who helped with the work, not including those listed as co-authors. The reference section lists all references in a format described in the journal submission guidelines. Using reference management software (such as Zotero, Mendeley, BibTex) makes organizing the references less cumbersome. A good scholarly research article should have citations for almost any claims made within the main body, to ensure proper connections to the prior research in the field.
Unlike patents, papers require a deep scientific background and should be straight to the point. While patents include all aspects of the idea, papers typically have space limitations, so should therefore be concise. The data in research articles should speak for itself. The language of a research paper should be clear and simple and not include metaphors or slang.

\section{Where to submit}

The submission target depends on several factors: (1) scope of the journal, (2) length of the paper (letters versus regular length articles), (3) access (regular versus open access), and (4) impact factor (IF). The scope of the journal is probably the first thing to consider; you cannot publish a biological paper in a humanity journal. Regarding length, a letter is much shorter and usually does not have section headings. It depends on the discipline, but sometimes letters are more favorable because of the shorter publication time, preparation simplicity, and more readability (takes less time to read, which may also improve the visibility of the paper). In terms of access, you may pay publication charges to receive open access, or some journals charge publication fees upon acceptance. Open access papers could potentially get more visibility than normal publications.

IF is a specific journal parameter indicating the average number of citations per published article over a certain period of time. Paying serious attention to IF could oppose the mission of science itself, as it could mean that you judge a paper only by where it is being published and not by its intrinsic values (also called high IF syndrome).

\section{Submission, peer-review, and decisions}

Your article will enter the peer-review process upon submission. If done properly, the peer-review process not only avoids false or inconsistent data from being published (and helps science in this regard), but also improves your paper and removes any potential errors/ issues or vague discussion. During submission, some journals may ask you to include/exclude reviewers. If there are researchers who may have a direct conflict with your work, you may list them as excluded reviewers. You may also suggest to include reviewers who have relevant experience.

Serving as a reviewer may help you with your own writing, as it assists in developing critical thinking. However, for the sake of science, try peer-reviewing for lesser-known journals (the highimpact journals already have many reviewers). Decisions on your article could be (1) reject: cannot be accepted to this journal; (2) referral to other journals; submit to another journal; (3) accept: accepted as is; (4) major revisions: not accepted, but could be accepted upon significant improvement (upon approval from reviewers); and (5) minor revision: accept but needs slight revisions (no need to go through a peer review again).

\section{Copyrights and archiving}

Most journals obtain copyrights from the authors before submission via a copyright transfer form. Hence, republishing the same data and plots in another journal is often forbidden. Also, the language of a paper should have a significant difference from an already published paper to avoid plagiarism. In the case where some content (e.g., figure or table) needs to be re-published in another paper (e.g., for review articles or thesis/dissertations), one can request a copyright permission from the original publishing journal. Also, archiving of one's published papers in personal profile websites (e.g., Researchgate or LinkedIn) is usually forbidden, unless the paper is published as open access. 


\section{Final tips for paper publication}

- Read, read, read! There is probably no better way of improving writing skills than reading other articles and books.

- Make illustrative and self-contained figures that can stand on their own.

- Know your audience when selecting a journal. Find out which journals are normally targeted by people in your research community.

- Protect yourself from high impact factor (IF) syndrome. Journals with a high IF may have very subjective decision criteria. It is sometimes more important to have your paper published than to spend a couple of years waiting for publication in a high-impact journal.

- Serve as a reviewer. Get a sense of how a peer-review process feels in order to establish critical thinking. Before submitting your article, self-review.

- Look forward to a constructive peer review. It definitely improves your paper (always good to have a view from different perspective).

- Enjoy your publications!

\section{$\mathrm{M}|\mathrm{R}| \mathrm{S} \bigcirc \mathrm{OnDemand} \mathrm{d}^{\ominus}$ WEBINAR SERIES}

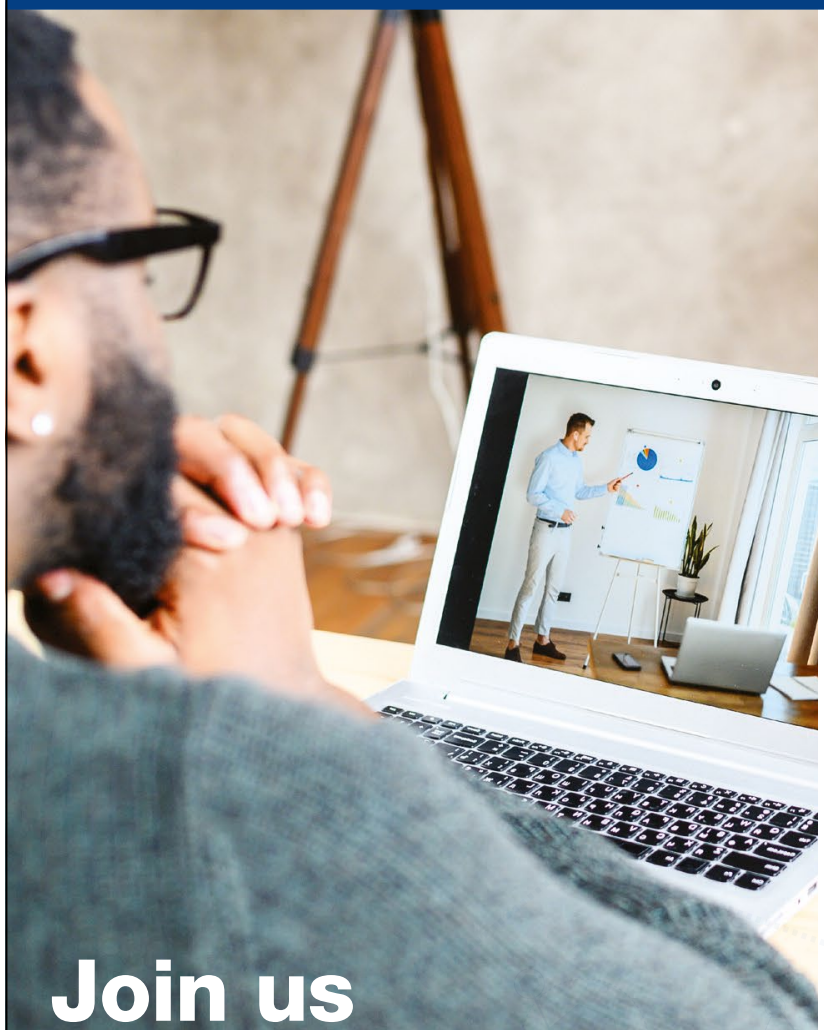

for our next online event mrs.org/webinars!

\section{UPCOMING WEBINARS}

\section{March 24, 2021}

Recent Development in Nanostructured Metals and Alloys Sponsored by Kammrath \& Weiss and Rigaku

- March 30, 2021

Hardness Testing of Soft Biomaterials and Hydrogels through Indentation Analysis

Presented by Anton Paar USA

\section{March 31, 2021}

Perovskites and Graphene: State-of-the-Art Materials for Advanced Applications

Presented by Goodfellow

\section{April 6, 2021}

Multifunctional materials for emerging technologies

Presented by National Tsing Hua University

\section{- April 7, 2021}

Potential and Challenges of Bioceramics Virtual Workshop Co-presented by MRS and ACerS

\section{$\checkmark$ April 21, 2021}

Materials Challenges in Soft Robotics

\section{May 26, 2021}

Materials Developments in Battery Safety Sponsored by CAMECA, Gatan and Rigaku 